\title{
MODELING THE WIND INFLUENCE IN AN OIL SPILL ALONG THE SOUTHERN BRAZILIAN SHELF
}

\begin{abstract}
C. E. Stringari ${ }^{\mathrm{a}}$,
W. C. Marques ${ }^{b}$,

L. F. Melloc, and R. T. Edit ${ }^{\mathrm{d}}$

${ }^{\mathrm{a}, \mathrm{d}}$ Universidade Federal do Rio Grande Instituto de Oceanografia Núcleo de Oceanografia Física Campus Carreiros: Av. Itália Km 8 Carreiros

Rio Grande, Rio Grande do Sul, Brasil caiodalaqua@hotmail.com

bUniversidade Federal do Rio Grande Instituto de Matemática Estatística e Física

${ }^{c}$ Universidade Federal do Rio Grande Cento de Ciências Computacionais

\section{ABSTRACT}

Oil spills can generate different effects in different time scales on the marine ecosystem. The numerical modeling of this process is an important tool with low computational cost which provides a powerful appliance to environmental agencies regarding the risk management. In this way, the objective of this work is evaluate the local wind influence in a hypothetical oil spill along the Southern Brazilian shelf. The numerical simulation was carried using the ECOS model (Easy Coupling Oil System), an oil spill model developed at the Universidade Federal do Rio Grande - FURG, coupled with the tridimensional hydrodynamical model TELEMAC3D (EDF, France). The hydrodynamic model provides the velocities, salinity and temperature fields used by the oil spill model to evaluate the behavior and fate of the oil. The results suggest that the local wind influence are the main forcing driven the fate of the spilled oil. The direction and intensity of the currents are important controlling the behavior and the tridimensional transportation of the oil, on the other hand, the turbulent diffusion is important for the horizontal drift of the oil. The weathering results indicate $40 \%$ of evaporation and $80 \%$ of emulsification, and the combination of these processes leads an increasing of the oil density around $53.4 \mathrm{~kg} / \mathrm{m}^{3}$ after 5 days of simulation.
\end{abstract}

\section{NOMENCLATURE}

$\mathrm{A}_{0} \quad$ spill initial area, $\mathrm{m}$

$\mathrm{A}_{\mathrm{s}} \quad$ evaporation area, $\mathrm{m}^{2}$

A evaporation constant

B evaporation constant

$\mathrm{D}_{\mathrm{x}}, \mathrm{D}_{\mathrm{y}}$ diffusion coefficients, $\mathrm{m}$

$d_{i} \quad$ droplet mean diameter, $m$

$d_{\max } \quad$ droplet maximum diameter, $\mathrm{m}$

$d_{\text {min }} \quad$ droplet minimum diameter, $\mathrm{m}$

$\mathrm{F}_{\mathrm{e}} \quad$ evaporation rate, $\mathrm{kg} / \mathrm{s}$

g gravity acceleration, $\mathrm{m}^{2} / \mathrm{s}$

$\mathrm{K}_{\mathrm{e}} \quad$ mass transfer coefficient

$\mathrm{k}_{1} \quad$ constant, $\mathrm{k}=0.57$

$\mathrm{k}_{2} \quad$ constant, $\mathrm{k}=0.72$

$\mathrm{k}_{\mathrm{c}} \quad$ current transport coefficient

$\mathrm{k}_{\mathrm{w}} \quad$ wind transport coefficient

$\mathrm{R}_{1}, \mathrm{R}_{2}$ random numbers

$\mathrm{S} \quad$ mixing length

$\mathrm{U}_{\mathrm{i}} \quad$ meridional tracer velocity, $\mathrm{m} / \mathrm{s}$

$\mathrm{U}_{\mathrm{c}}$ meridional current velocity, $\mathrm{m} / \mathrm{s}$

$\mathrm{U}_{\mathrm{w}} \quad$ meridional wind velocity, $\mathrm{m} / \mathrm{s}$

Us meridional spreading velocity, $\mathrm{m} / \mathrm{s}$

$\mathrm{U}_{\mathrm{r}} \quad$ meridional spreading ratio, $\mathrm{m}$

Ud meridional turbulent velocity, $\mathrm{m} / \mathrm{s}$

$\mathrm{V}$ spilled volume, $\mathrm{m}^{3}$

$\mathrm{V}_{\mathrm{i}} \quad$ zonal tracer velocity, $\mathrm{m} / \mathrm{s}$

$\mathrm{V}_{\mathrm{c}} \quad$ zonal current velocity, $\mathrm{m} / \mathrm{s}$

$\mathrm{V}_{\mathrm{w}} \quad$ zonal wind velocity, $\mathrm{m} / \mathrm{s}$

Vs zonal spreading velocity, $\mathrm{m} / \mathrm{s}$
Keywords: Oil Spill, Numerical Modeling, Wind influence.
Vd zonal turbulent velocity, $\mathrm{m} / \mathrm{s}$

$\mathrm{V}_{\mathrm{r}} \quad$ zonal spreading ratio, $\mathrm{m}$

$\mathrm{W}_{\mathrm{w}}$ modular wind velocity, $\mathrm{m} / \mathrm{s}$

$\mathrm{W}_{\mathrm{i}} \quad$ vertical tracer velocity, $\mathrm{m} / \mathrm{s}$

$\mathrm{W}_{\mathrm{c}} \quad$ vertical current velocity, $\mathrm{m} / \mathrm{s}$

W vertical tracer buoyancy, $\mathrm{m} / \mathrm{s}$

$\mathrm{T}$ temperature, $\mathrm{K}$

$\mathrm{T}_{\mathrm{g}} \quad$ distillation gradient

$\mathrm{T}_{\mathrm{o}} \quad$ ebullition point

$\mathrm{t}$ time, $\mathrm{s}$

$\mathrm{x}, \mathrm{y}, \mathrm{z}$ tracers positions, $\mathrm{m}$

\section{Greek symbols}

$\Delta \quad$ discrete differential operator

$v$ fluid kinematic viscosity, $\mathrm{m}^{2} / \mathrm{s}$

$\sigma \quad$ wave energy, $\mathrm{J}$

$\rho$ density, $\mathrm{kg} / \mathrm{m}^{3}$

$\omega \quad$ wave period

\begin{tabular}{|c|c|}
\hline Subs & ripts \\
\hline 1 & tracer index \\
\hline $\max$ & maximum \\
\hline $\min$ & minimum \\
\hline o & oil \\
\hline $\mathrm{W}$ & water \\
\hline
\end{tabular}




\section{INTRODUCTION}

The outpouring of oil and derivatives on the marine ecosystem is an important subject to be considered by the modern society, since the oil is composed by toxic substances that exposed on the environment can create chronic effects (Burns, 1994). In this way, the efficient recovering of the affected region can take dozens to hundreds years, or even be irreversible, affecting the society in different ways. According with Clark (2001), a half of the world oil production is transported by the oceans, meaning 31.5 billion gallons. Fernandes (2001) suggests that the oil entrance on the marine environment varies from 1.7 to 8.8 million tons/year, where the marine transportation is responsible for $23.5 \%$ of this total, while much concerns in regular ship operations, and a small part (about 10\%) represent the accidental spills. According with Pereira (2002) the routine operations in harbors, accidents in transport terminal networks and urban effluents have been the major oil sources for the ocean.

The Southern Brazilian Shelf (Figure 1A) presents high susceptibility for eventual accidents regarding the oil spill, since nowadays, there is a intense oil transportation in this region due to the Rio Grande Harbor, the Transpetro Waterway Terminal (Petrobras) and the Riograndense Oil Refinery S/A. The major part of the transportation activities identified in this region occur on the estuarine environment of the Patos Lagoon and near the adjacent coastal region.

The oil spill in estuaries is worrying because these are ecological and economically important environments. The estuaries retain a large amount the spilled oil, increasing the contamination effects. Therefore, the estuaries are the environments that present the major sensibility degree according with the scales used in the oil sensitivity maps.

According with the Brazilian legislation, the numeric simulations of spilled oil must define the area of indirect influence of this activity, in which all the environment diagnostic is based. In this sense, the diagnostic defines and simulates scenarios allowing the development of strategies for an oil spill accident in the ocean into the emergency plane of the companies. Therefore, the objective of this paper is investigate the effects of different physical forcing controlling the behavior and the fate of an oil spill near the Patos Lagoon entrance.

\section{HYDRODINAMIC MODEL}

The numerical model TELEMAC3D (EDF Laboratoire National d' Hydraulique et Environnement of the Company Eletrecité de France) has been used for tridimensional hydrodynamic simulations. This model solves the
Navier-Stokes Eqs using finite element techniques for spatial discretization. It considers the free surface variation for incompressible fluids and it considers the Boussinesq approximation in order to solve the momentum Eqs. (Hervouet, 2007). A detailed discussion regarding the TELEMAC3D, the calibration and validation tests for hydrodynamics and morphodynamics along the Southern Brazilian Shelf can be found in Marques et al. (2009, 2010a, 2010b). Figure 1 shows study region and the numeric mesh of the simulations.

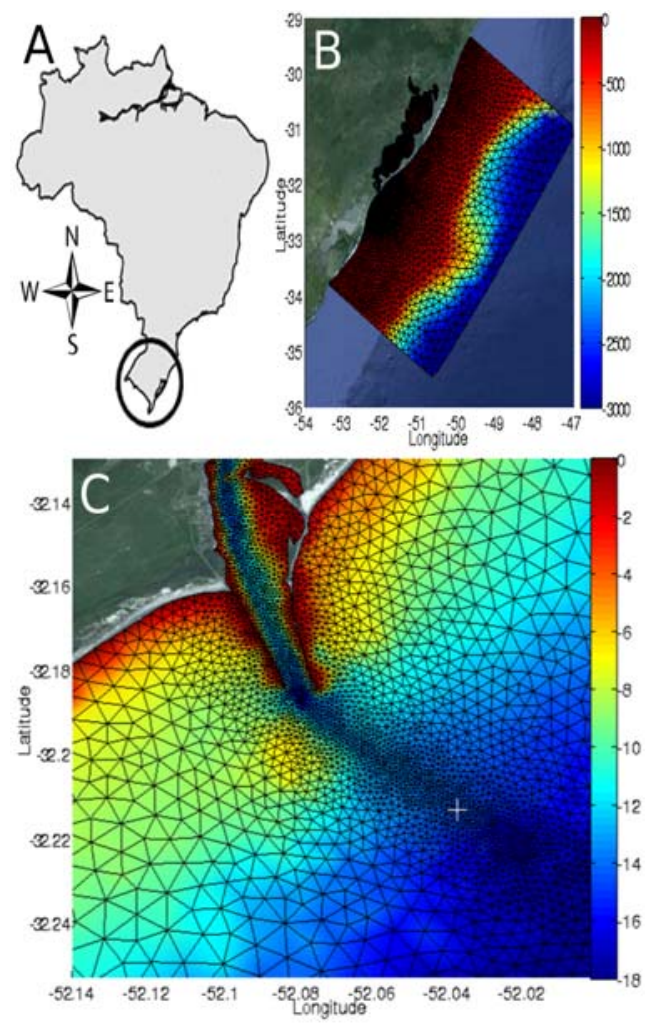

Figure 1. Study region. Color bars indicates bathymetric variations. Cross signal indicates the center of oil spill.

\section{THE ECOS MODEL}

The ECOS (Easy Coupling Oil Model) has been developed through techniques of modular programming, which allows a better structuring and control of the libraries related to the subprograms and functions. This type of organization allows the compilation of each module apart, saving computational time, so that the reutilization of the functions is facilitated. The model uses a coupling interface, which contains all the necessary information to be shared by the oil and hydrodynamic model. The processes of oil are subject when arrives at the environment, such as: spreading, turbulent diffusion, evaporation, dispersion and emulsification are implemented. 


\section{BRIEF MATHEMATICAL DESCRIPTION OF OIL TRANSPORT AND WEATHERING PROCES}

This section quickly describes the mathematical formulations used by some actual oil models and those used by the ECOS model developed at the FURG. This model treats oil like discrete particles using Lagrangian approximation to evaluate the tracer (particles) proprieties during time.

The tracer trajectories are evaluated considering the oil like a large number of particles which moves independently in water. The tracer velocities are interpolated from the current velocity in each node of the hydrodynamic numerical domain (Figure 1B and Figure 2). The final tracer position is dependent from four different factors: (1) Current velocity, (2) Wind velocity, (4) the spreading effect and (4) the turbulent diffusion. In this work, the effects associated with slick drift are described in following sections. The Figure 3 shows all the process acting in an oil spill at marine environment.

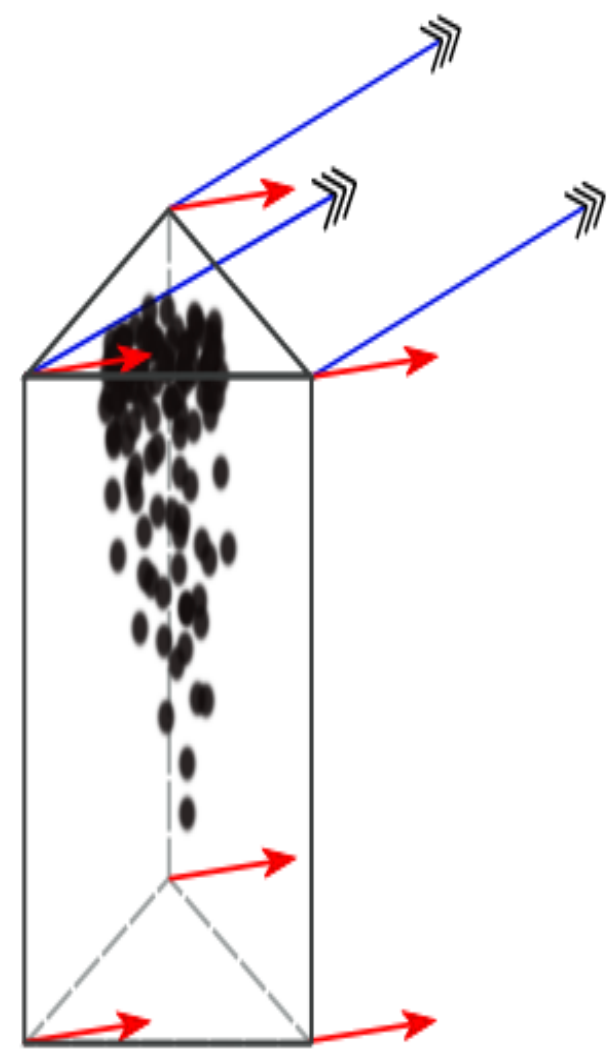

Figure 2. Advective forces on a generic element. Blue vectors indicate wind contribution and red vector indicate current contribution; the final path of each particle is algebraic interpolation of this forces.

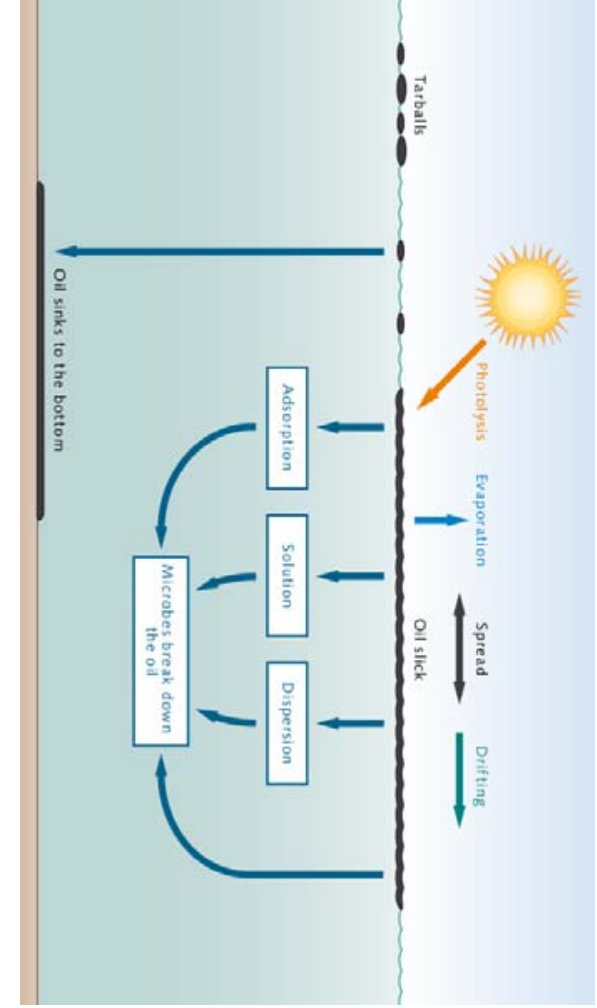

Figure 3. Oil weathering processes in marine environments. Bollman et al. (2010).

\section{ADVECTION}

In this work, all the effects which are independent from the physical-chemical effects are considered like advective forcing. In these classes are evaluated the drifting driven by the current and wind, and also the vertical transport due to the buoyancy associated to the difference of density of the oil and water.

$$
\begin{gathered}
\mathrm{U}_{\mathrm{i}}=\left(\mathrm{K}_{\mathrm{c}} \mathrm{U}_{\mathrm{c}}\right)+\left(\mathrm{K}_{\mathrm{w}} \mathrm{U}_{\mathrm{w}}\right) \\
\mathrm{V}_{\mathrm{i}}=\left(\mathrm{K}_{\mathrm{c}} \mathrm{V}_{\mathrm{c}}\right)+\left(\mathrm{K}_{\mathrm{w}} \mathrm{V}_{\mathrm{w}}\right) \\
\mathrm{W}_{\mathrm{i}}=\left(\mathrm{K}_{\mathrm{c}} \mathrm{W}_{\mathrm{c}}\right)+\mathrm{w}_{\mathrm{i}}
\end{gathered}
$$

The zonal $(U)$, meridional $(V)$ and vertical (W) components of the velocity are calculated by the Eqs. $(1,2,3)$, respectively.

$$
\mathrm{w}_{\mathrm{i}}=\mathrm{gd}_{\mathrm{i}} \frac{1-\frac{\rho_{\mathrm{o}}}{\rho_{\mathrm{w}}}}{18 \mathrm{v}_{\mathrm{w}}}
$$

The particle buoyancy law in Eq. (4) is based in a modified stokes law for the oil according with French-Mccay (2004) and Chao et al (2001). 


$$
\begin{gathered}
\mathrm{d}_{\text {max }}=\sqrt{\frac{12 \sigma}{\mathrm{g}\left(\rho_{\mathrm{w}}-\rho_{\mathrm{o}}\right)}} \\
\mathrm{d}_{\text {min }}=\frac{0.12 \sigma^{3 / 5} \omega^{2 / 5}}{\mathrm{~g}^{4 / 5} \rho_{\mathrm{w}}^{3 / 5}} \\
\mathrm{~d}_{\mathrm{i}}=\frac{\mathrm{d}_{\text {min }}+\mathrm{d}_{\text {max }}}{2}
\end{gathered}
$$

Maximum and minimum droplets sizes are evaluated through Al-Rabeh et al (1989) formulations in Eq. (5) and (6). Thus, the mean droplet size is an arithmetic mean of the maximum and minimum droplets size in Eq. (7).

\section{DIFFUSION}

The spreading is an horizontal expansion effect due to the different superficial tensions between water and oil. This represents a force balance between gravity acceleration, inertia, viscous and superficial tensions. This process is very important during initial moments after spill.

The algorithm used to evaluate oil spreading determines the random velocities $U_{d}$ and $\mathrm{V}_{\mathrm{d}}$ uniform distribution in the range $\left[-\mathrm{U}_{\mathrm{r}}+\mathrm{U}_{\mathrm{r}}\right]$ and $\left[-\mathrm{V}_{\mathrm{r}}+\mathrm{V}_{\mathrm{r}}\right]$ (in $\mathrm{x}$ and $\mathrm{y}$ directions, respectively) proportional to the diffusion coefficients, which are calculated assuming that the Lagrangian tracers spread according with the solution proposed by Fay (1969).

$$
\mathrm{D}_{\mathrm{x}}=\mathrm{D}_{\mathrm{y}}=\frac{\pi \mathrm{k}_{2}^{2}}{16}\left(\frac{\Delta \mathrm{gV}^{2}}{\mathrm{v}_{\mathrm{w}}^{2}}\right)^{\left(\frac{1}{3}\right)} \cdot \frac{1}{\sqrt{\mathrm{t}}}
$$

The relationship between the diffusion coefficients $D_{x}$ and $D_{y}$ and the interval of the flotation velocity $\left[-\mathrm{U}_{\mathrm{r}}+\mathrm{U}_{\mathrm{r}}\right]$ and $\left[-\mathrm{V}_{\mathrm{r}}+\mathrm{V}_{\mathrm{r}}\right]$ are adopted according with Leitão (1996). The diffusion coefficients $D_{x}$ and $D_{y}$ are calculated according Eq. (8):

$$
\left(\mathrm{U}_{\mathrm{r}}, \mathrm{V}_{\mathrm{r}}\right)=\sqrt{\frac{2\left(\mathrm{D}_{\mathrm{x}}, \mathrm{D}_{\mathrm{y}}\right)}{\Delta \mathrm{t}}}
$$

The intervals of flotation $\left[-U_{r},+U_{r}\right]$ and $\left[-V_{r},+V_{r}\right]$ are calculated according with the Eqs. $(9,10)$.

$$
\begin{aligned}
& \mathrm{U}_{\mathrm{si}}=\mathrm{R}_{1} \cos \left(2 \pi \mathrm{R}_{2}\right) \mathrm{U}_{\mathrm{r}} \\
& \mathrm{V}_{\mathrm{si}}=\mathrm{R}_{1} \operatorname{sen}\left(2 \pi \mathrm{R}_{2}\right) \mathrm{V}_{\mathrm{r}}
\end{aligned}
$$

The random velocities are, therefore, determined by the formulation proposed by Proctor et al. (1994) in Eqs. (11,12).

\section{TURBULENT DIFFUSION}

The horizontal turbulent diffusion is evaluated though a modified mixing length turbulence model for oil spills.

$$
\begin{aligned}
& \Delta \mathrm{S}=\mathrm{R}_{1} \sqrt{12 \mathrm{D}_{\mathrm{x}} \Delta \mathrm{t}} \\
& \mathrm{U}_{\mathrm{di}}=\cos \left(2 \pi \mathrm{R}_{2}\right) \\
& \mathrm{V}_{\mathrm{di}}=\sin \left(2 \pi \mathrm{R}_{2}\right)
\end{aligned}
$$

Maximum distance which a particle can go from actual (t) position is calculated from Eq. (13), equivalent a traditional mixing length model. Eqs. $(14,15)$ estimates particles velocities based in a "random walk" method.

\section{PARTICLE PATH}

Finally, after definition of all the forces acting in a particle, the positions can be integrated in time, by a forward Euler method.

$$
\begin{aligned}
& \mathrm{x}_{\mathrm{i}}^{\mathrm{t}+\Delta \mathrm{t}}=\mathrm{x}_{\mathrm{i}}^{\mathrm{t}}+\Delta \mathrm{t} \cdot\left(\mathrm{U}_{\mathrm{i}}^{\mathrm{t}}+\mathrm{U}_{\mathrm{Si}}^{\mathrm{t}}+\mathrm{U}_{\mathrm{di}}^{\mathrm{t}}\right) \\
& \mathrm{y}_{\mathrm{i}}^{\mathrm{t}+\Delta \mathrm{t}}=\mathrm{y}_{\mathrm{i}}^{\mathrm{t}}+\Delta \mathrm{t} \cdot\left(\mathrm{V}_{\mathrm{i}}^{\mathrm{t}}+\mathrm{V}_{\mathrm{Si}}^{\mathrm{t}}+\mathrm{U}_{\mathrm{di}}^{\mathrm{t}}\right) \\
& \mathrm{z}_{\mathrm{i}}^{\mathrm{t}+\Delta \mathrm{t}}=\mathrm{z}_{\mathrm{i}}^{\mathrm{t}}+\Delta \mathrm{t} \cdot\left(\mathrm{W}_{\mathrm{i}}^{\mathrm{t}}+\mathrm{W}_{\mathrm{i}}^{\mathrm{t}}\right)
\end{aligned}
$$

The Eqs. $(16,17,18)$ evaluates each particle positions during time.

\section{EVAPORATION}

Evaporation is considered the most important process in an oil spill, once this controls the mass balance and it can causes about $75 \%$ of lost mass according with Fingas (1998). Evaporation processes are linked with the wind velocity and the spill area.

$$
\frac{\mathrm{dF}_{\mathrm{e}}}{\mathrm{dt}}=\frac{\mathrm{K}_{\mathrm{e}} \mathrm{A}_{\mathrm{s}}}{\mathrm{V}_{0}} \cdot \exp \left(\mathrm{A}-\frac{\mathrm{B}}{\mathrm{T}}\left(\mathrm{T}_{\mathrm{o}}+\mathrm{T}_{\mathrm{G}} \mathrm{F}_{\mathrm{e}}\right)\right)
$$

The evaporation rates are determined according with Stiver and Mackay (1984) by the Eq. (19). 


\section{EMULSIFICATION}

The creation of a mousse, mainly characteristic of this process, occurs due to the incorporation of water in oil slick through the polar components of the oil.

$$
\frac{\mathrm{dF}_{\mathrm{wv}}}{\mathrm{dt}}=\mathrm{K}_{\mathrm{w}}(1+\mathrm{W})^{2}\left(1-\frac{\mathrm{F}_{\mathrm{wv}}}{\mathrm{F}_{\mathrm{wv}}^{\mathrm{final}}}\right)
$$

The Eq. (20) represents the water incorporation in oil according with Mackay et al (1980).

\section{OIL DENSITY}

This process is very important in the oil spill modeling, once the buoyancy of the oil particles are determined. This causes the sinking of the oil if the water density is lower than the oil density. In a quickly view, during the evaporation process occurs mass lost, while during the emulsification process occurs mass gain of the oil slick. Therefore, the balance of these processes define the final oil density.

$$
\begin{aligned}
& \rho=\mathrm{F}_{\mathrm{wv}} \rho_{\mathrm{w}}+\ldots \\
& \rho_{\mathrm{o}}\left(1-\mathrm{F}_{\mathrm{wv}}\right)\left(1+\mathrm{C}_{\mathrm{DE}} \mathrm{F}_{\mathrm{e}}\right)\left[1-\mathrm{C}_{\mathrm{DT}}\left(\mathrm{T}-\mathrm{T}_{0}\right)\right]
\end{aligned}
$$

The Eq. (21) evaluates the oil density according with Buchanan and Hurford (1988).

\section{THE COUPLING BETWEEN TELEMAC3D AND ECOS MODEL}

The ECOS model had been directly coupled to the TELEMAC3D source code (see Mello et al, 2012). In the TELEMAC3D, the hydrodynamics and the winds are used by the Lagrangian module for the oil model evaluates the tracers positions at each time step.

The salinity, temperature, and the density of the water, from the TELEMAC3D, are transferred by the weathering module which evaluate the oil evaporation, emulsification and density. Figure 4 shows the coupling between these models.

\section{BOUNDARY CONDITIONS}

The application of the numerical models require time series of oceanographic data, which are used as boundary conditions. The boundary conditions currently implemented include series of river discharge, water levels, salinity, temperature, current and wind velocity. The river discharge were obtained by the ANA web page - Agência Nacional de Águas (www.ana.gov.br, 2012).

Salinity, temperature, current velocity and water levels were obtained by the global predict model OCCAM - Ocean Circulation and Climate Advanced Model (www.soc.soton.ac.uk, 2012). Wind and air temperature data were provided for the NOAA page - National Oceanic \& Atmospheric Administration (www.cdc.noaa.gov/cdc/reanalysis, 2012).

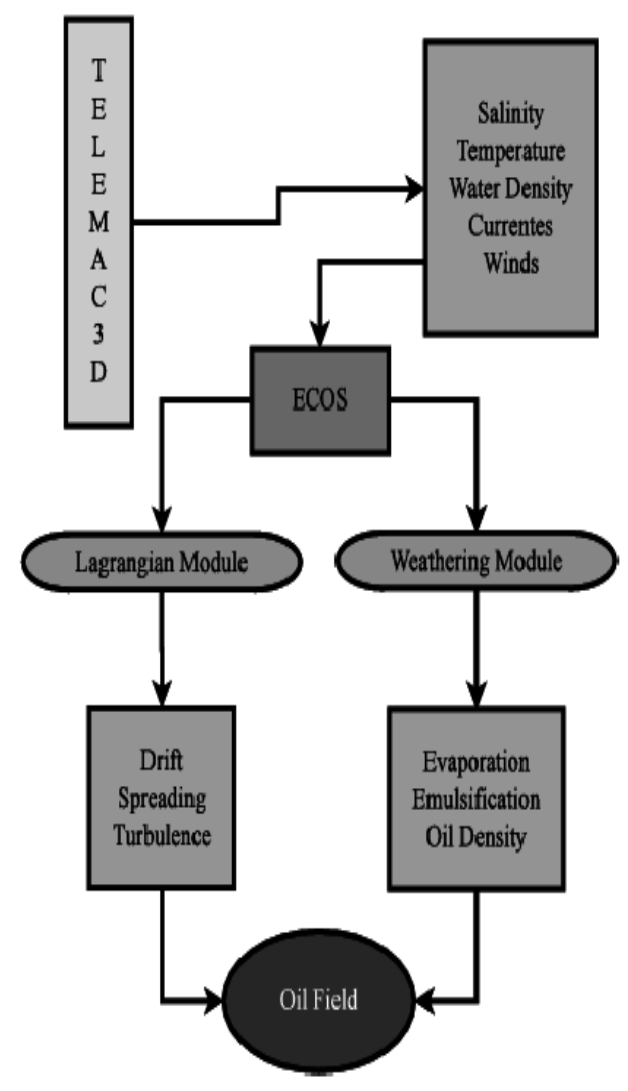

Figure 4. Information flux between models.

\section{INITIAL CONDITIONS AND OIL PROPERTIES}

Nowadays, the oil model consider an accidental punctual spill (see Figure 1B), with a circular form which can be estimated by Fay (1969) formulations. Once the initial gravitationalinertial phase are extreme quickly, the spilled initial area is defined at the end of this phase with the beginning of the gravitational-viscous phase in Eq. (22).

$$
\mathrm{A}_{0}=\pi \frac{\mathrm{k}_{2}^{4}}{\mathrm{k}_{1}^{2}} \sqrt[6]{\frac{\left(\frac{\rho_{\mathrm{w}}-\rho_{\mathrm{o}}}{\rho_{\mathrm{o}}}\right) g \mathrm{~V}_{0}^{6}}{v}}
$$


In this work, the initial conditions of the oil model are:

Amount of spilled oil
Salty water density
Fresh water density
Oil initial density
Water viscosity
Tracer Volume
$\Delta t$
$\mathrm{~K}_{\mathrm{w}}$
$\mathrm{K}_{\mathrm{c}}$

$$
\begin{aligned}
& 2000 \mathrm{~m}^{3} \\
& 1025 \mathrm{~kg} / \mathrm{m}^{3} \\
& 1000 \mathrm{~kg} / \mathrm{m}^{3} \\
& 980 \mathrm{~kg} / \mathrm{m}^{3} \\
& 0.89 .10^{6} \mathrm{~m}^{2} . \mathrm{s} \\
& 0.05 \mathrm{~m}^{3} \\
& 90 \mathrm{~s} \\
& 0.3 \\
& 1
\end{aligned}
$$

\section{RESULTS AND DISCUSSION}

In order to accomplish the objectives two simulations were carried out. The first simulation (simulation 1) includes all the physical forcing the oil slick dynamics. On the other hand, the second simulation (simulation 2) was carried out without consideration of the local wind influence over the oil slick.

The results regarding only the hydrodynamic processes are analyzed in this work, because an extensive description of hydrodynamic processes along the Southern Brazilian Shelf can be found in: Mello et. al. (2012), Stringari et all (2012) and Marques et al (2009, 2010a, 2010b).

\section{SIMULATION 1}

Results for the temporal evolution of the tracers are presented in Figure 5 (Salinity is represented by the reddish colors).

After the spill occurs a quickly initial horizontal expansion due to the spreading effect and the horizontal turbulence. The local wind over the oil slick controls the behavior and the final fate of those tracer, but past 30 hours of simulation the oil slick reaches the coastline.

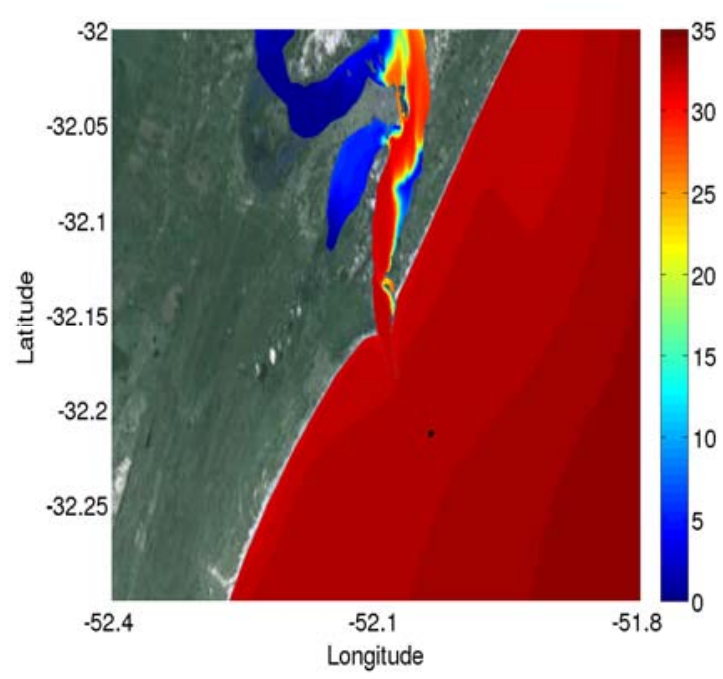

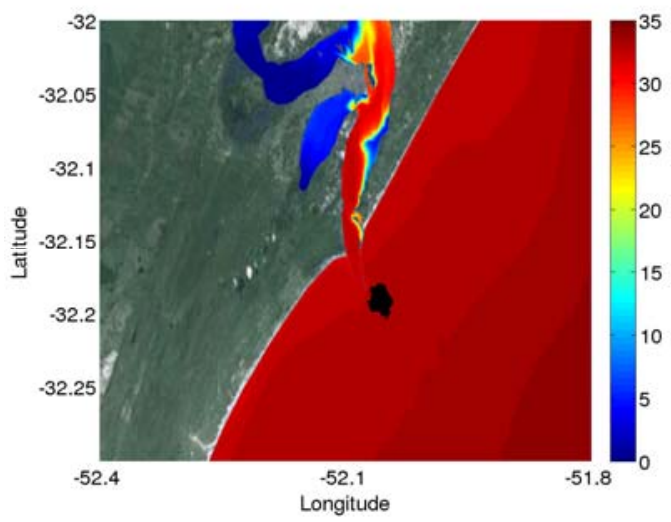
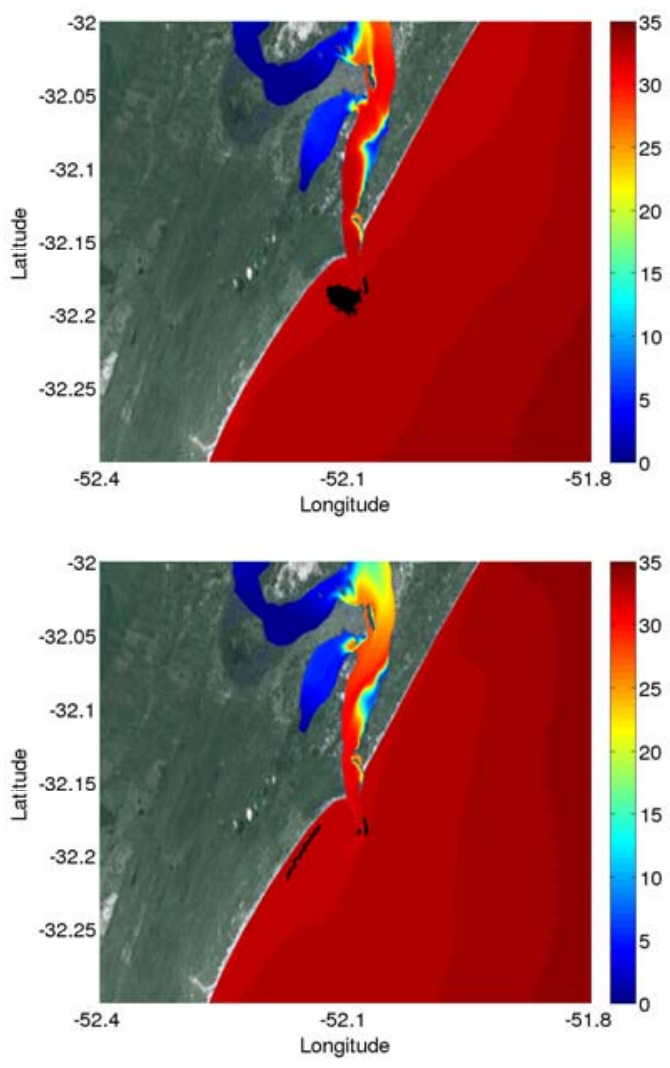

Figure 5. Evolution of particle path in intervals of 10 hours from each other.

Through the analyzes of the wind direction in Figure 6, it becomes clear that south quadrant winds are dominant in the first 20 hours of simulation followed afterwards by the north quadrant winds in the last hours. The south quadrant winds are downwelling favorable along the Southern Brazilian Shelf and this effect is observed on the oil slick behavior during the spreading in direction of the coastline. The behavior observed by the oil slick is very similar to the Patos Lagoon coastal plume studied by Marques et al (2009, 2010a and 2010b). 


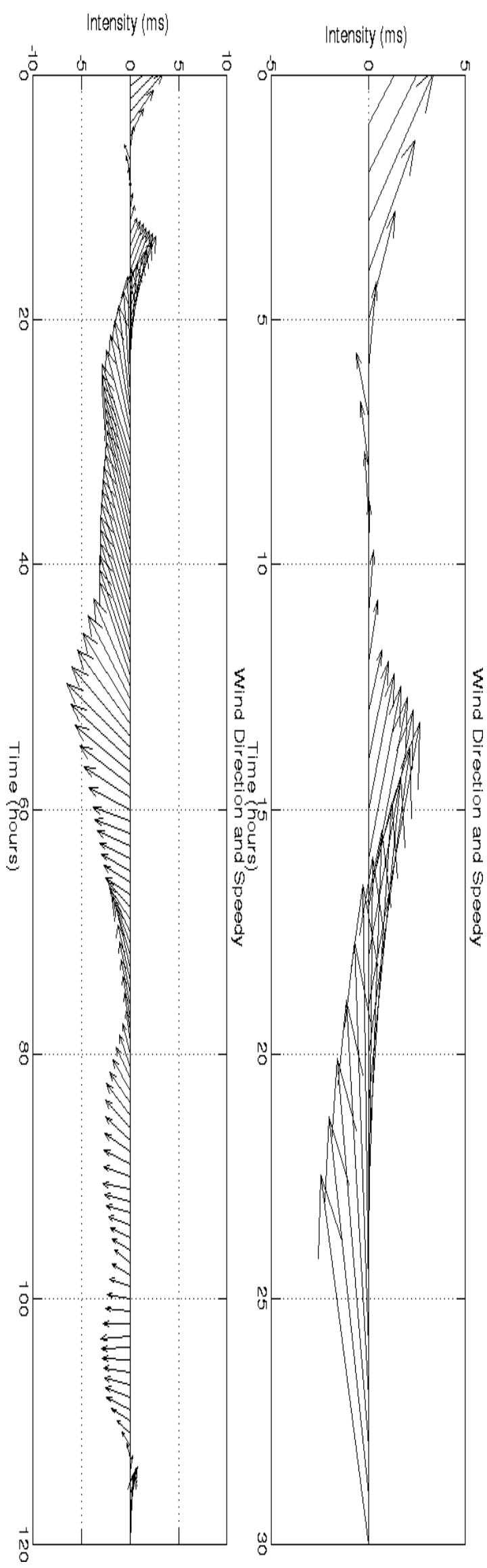

Figure 6. Time series of the average intensity of the forcing acting on the oil in the whole period.

\section{SIMULATION 2}

Results without local wind influence action over the oil slick are presented in Figure 7. The initial steps of the simulation are quite similar to the simulation considering the all forcing together, with dominance of the diffusive processes. However the oil slick never reaches coastline during the 5 days of simulation, because the influence of the local wind effects is not considered.
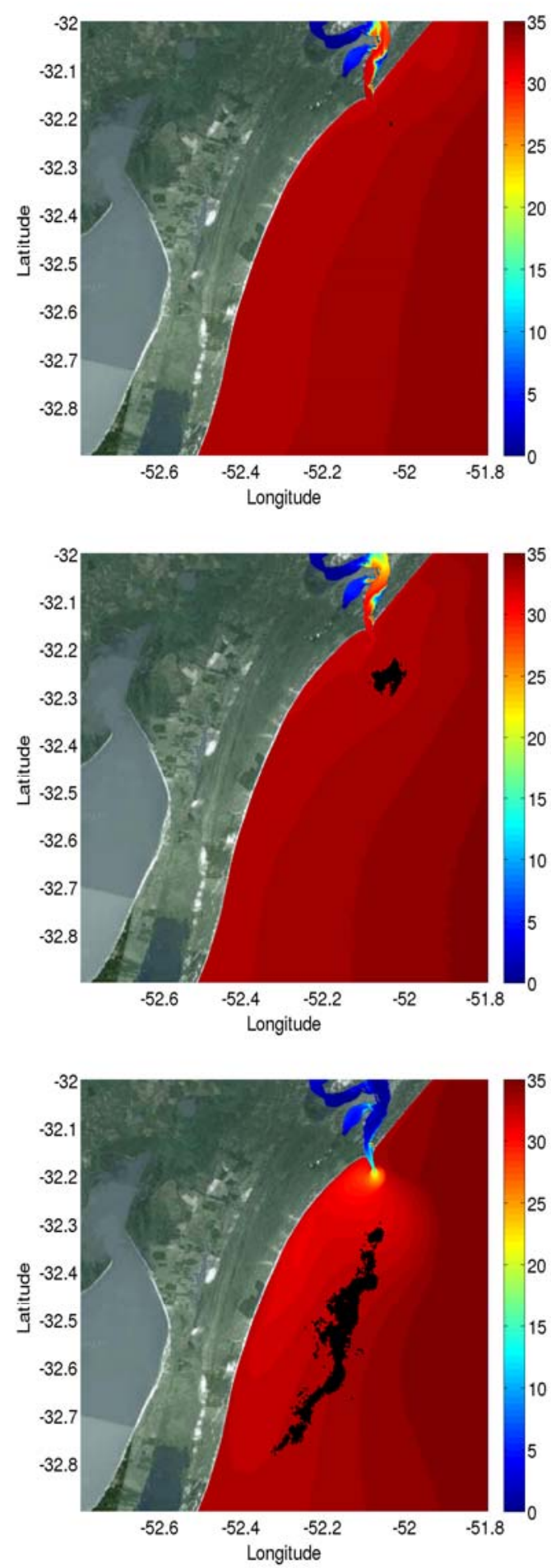


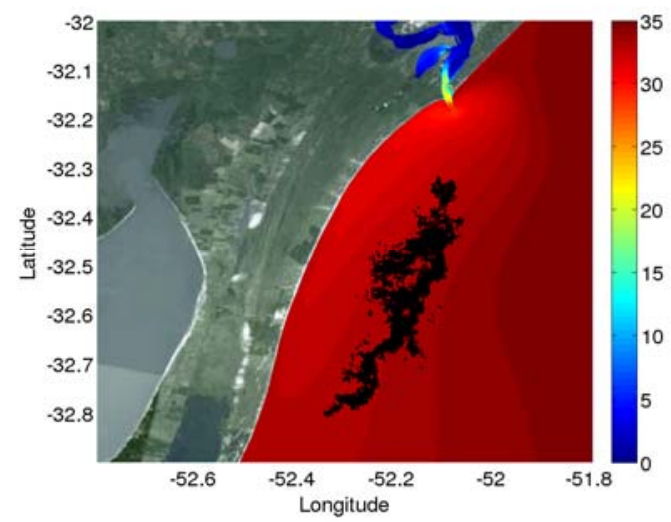

Figure 7. Evolution of particle path in intervals of 30 hours from each other.

The oil slick behavior and its further destination is strongly influenced by the coastal wind driven circulation pattern with the alongshore drifting to the south region due to northeastern winds. This behavior is consistent with results obtained by Marques et al. (2009, 2010a and 2010b) among others, for the coastal circulation near the Patos Lagoon entrance.

Several authors have shown the importance of the local wind influence for the oil drift patterns. For some huge accidents, like Amoco Cadiz or Exxon Valdes, it was observed that the wind intensity and direction, and also the spilled volume, are directly linked to the proportion of the affected area. Recent studies in Asiatic near shore waters by the Wang et al (2008) and Wang and Guo (2009) have shown similar results confirming the importance of the local wind effects acting over the oil slick controlling its behavior and the further destination.

\section{ANALYSIS OF THE PHYSICAL FORCING}

In order to quantify the contribution of the local wind effect as determinant factor controlling the oil slick behavior, a time series analysis is presented. The Figure 8 shows all the forcing acting on the oil slick during the period of simulation (120 hours). The results suggest that the wind effects appear as the most important contribution during almost all the time of simulation, except for the first few hours when the currents dominate the spreading of the spilled oil.

The second major contribution is provided by the coastal currents which carry the oil primarily on the direction of the superficial circulation moved by the wind, except by the particles that suffer processes of sinking according to the following tridimensional circulation pattern developed.

The turbulent forces act in a secondary way, generating a horizontal disintegration of the oil slick during all the period. The spreading speed decreases very fast, being active on the first hours of simulation, however this is determinant for the initial disintegration of the slick.

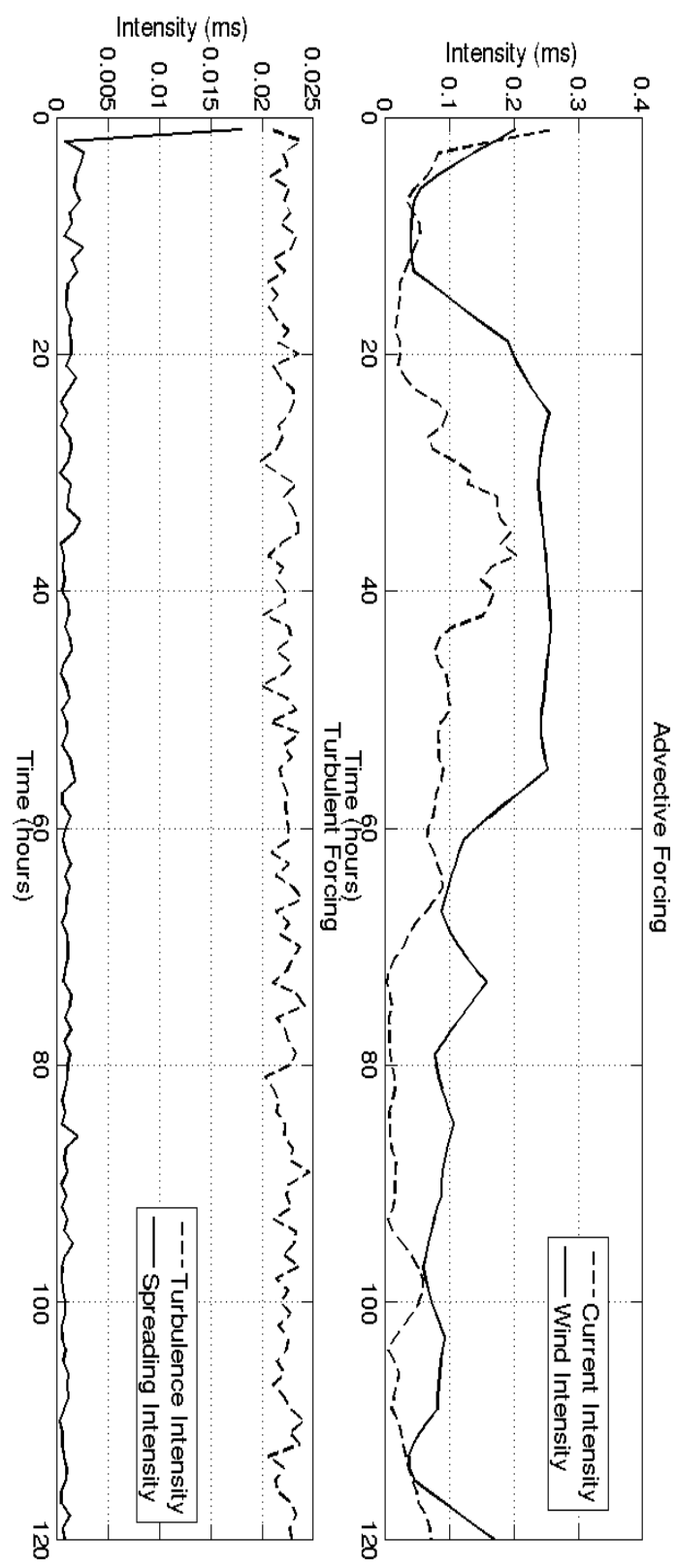

Figure 8. Forces acting on oil slick in whole simulation.

\section{WEATHERING PROPERTIES}

On the analysis of the tracer trajectories is not enough information to explain the oil spill behavior. Therefore is necessary consider the analysis of the scalar properties, such: evaporation and emulsification, that directly influence the oil density.

Figure 9 shows the temporal evolution of the scalar properties calculated by the oil model. It is possible observe that a great amount of the oil evaporates (around 40\%) and emulsifies (around 
$70 \%$ ) during the first 48 hours of simulation. The combination of the emulsification and evaporation effects cause some increase in the oil density.
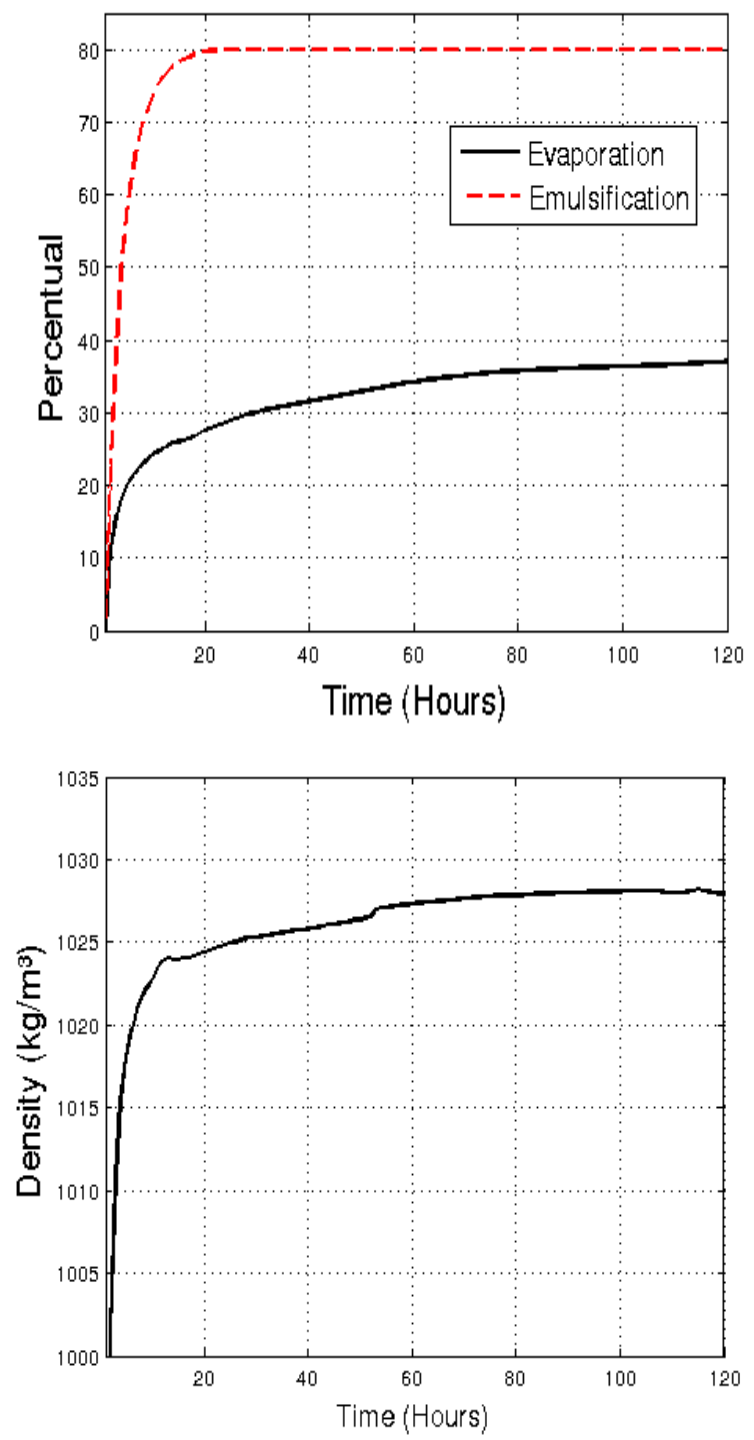

Figure 9. Time series of the scalar properties of the oil.

The behavior of the emulsification is corroborated by the experiments proposed by Wang and Huang (1979) that analyzing an emulsions series showed that the curve follows a exponential pattern with a quick incorporation of water during the first 24 hours. The evaporation behavior is consistent with the results observed in Chao et all (2001) and by the model ADIOS2 (NOAA, 2000).

The increase of the oil density makes it reach a density very close to the salt water, which causes a balance of phases enhancing the importance of the effects controlled by the tridimensional circulation causing processes such as vertical dissolution and sedimentation of the spilled oil.

\section{CONCLUSIONS}

The principal conclusions obtained in this study are:

The wind acting over the oil slick is the most important forcing controlling its behavior and the further destination. The winds from the South (North) quadrant induce the movement of the oil slick directly to the coast (offshore).

The intensity and direction of the coastal currents are important for the vertical distribution of the oil along the water column. The diffusive forcing has a secondary effect acting mainly on the horizontal dispersion of the oil slick.

During the 120 hours of simulation about $40 \%$ of the oil evaporates and $80 \%$ of the oil emulsificates. The combination of these effects generate an increase of the $53.4 \mathrm{~kg} / \mathrm{m}^{3}$ on density showing the magnitude of the mixture and the aging processes.

Simulation without the consideration of the wind on the oil slick is slack realistic because the oil slick does not reach the coast any moment even by the acting of favorable winds. Besides, after 48 hours of simulation, the aging processes are dominant and, in some way, it commits the results obtained by the spreading of the oil slick after this period.

\section{ACKNOWLEDGEMENTS}

The authors thank to the Conselho Nacional de Desenvolvimento Científico e Tecnológico CNPQ and the Agência Nacional do Petróleo ANP for the fellowships provided which helped the development of this work. Further acknowledgements go to the Fundação de Amparo à Pesquisa do Estado do Rio Grande do Sul FAPERGS for partially support this work (Process 11/1767-4).

\section{REFERENCES}

Al-Rabeh, A. H., Cekirge, H. M., and Gunay, N., 1989, A Stochastic Simulation Model of Oil Spill Fate and Transport, Applied Mathematical Modelling, Vol. 13, pp. 322-329.

Bollmann, M., Thomas, B. F. C., Ralf, E., Rainer, F. K. G., Setareh, K., Krastel, A. K. S., Langenbuch, M., Latif, B. M. M., Melzner, F., Oschlies, S. P. A., Proelß, A., Quaas, J. R. M., Requate, T., and Reusch, T. P. R., 2010, World Ocean Review, Maribus.

Buchanan, I., and Hurford, N., 1988, Methods for Predicting the Physical Changes in Oil Spilt at Sea, Oil \& Chemical Pollution, pp. 311-328.

Burns, K. A., Garrity, S., Jorissen, D., Macpherson, J., Stoelting, M., Tierney, J., and Simmons, L. Y., 1994, The Galeta Oil Spill Ii - 
Unexpected Persistence of Oil Trapped in Mangrove Sediments Morlaix Twenty Years After the Amoco Cadiz Oil Spill, Estuarine, Coastal and Shelf Research, Vol. 38, pp. 349-364.

Chao, X., Shankar, N. J., and Cheong, H. F., 2001, Two-And Three-Dimensional Oil Spill Model for Coastal Waters, Ocean Engineering, Vol. 28, pp. 1557-1573.

Clark, R. B., 2001, Marine Pollution, Oxford: Press, Oxford University, pp. 248.

Fay, J. A., 1969, The Spread of Oil Slicks on a Calm Sea, Oil on the Sea, Plenum Press.

Fernandes, R. M., 2001, Modelação de Derrames de Hidrocarbonetos, Doctoral Thesis, Instituto Superior Técnico - Universidade de Lisboa. (in Portuguese)

Fingas, M., 1998, The Evaporation of Oil Spills: Development and Implementation of New Prediction Methodology, in: Marine Environmental Modelling Seminar, Lillehammer, Norway.

French-Mccay, D. P., 2004, Oil Spill Impact Modeling: Development and Validation. Environmental Toxicology an Chemistry, Vol. 23(10), pp. 2441-2456.

Hervouet, J. M., 2007, Free Surface Flows: Modelling with Finite Element Methods, John Wiley and Sons.

Leitão, P., 1996, Modelo De Dispersão Lagrangeano Tridimensional, Masther Thesis, Universidade Técnica de Lisboa. (in Portuguese)

Mackay, D., Buistt, I. A., Mascarenhas, R., and Paterson, S., 1980, Oil Spill Processes And Models, Technical Report, Ottawa, Ontario.

Marques, W. C., Fernandes, E. H., Monteiro, I. O., and Möller, O. O., 2009, Numerical Modeling of the Patos Lagoon Coastal Plume, Brazil, Continental Shelf Research, Vol. 29(3), pp. 556-571.

Marques, W. C, Fernandes, E. H. L., and Moller, O. O., 2010a, Straining and Advection Contributions to the Mixing Process of the Patos Lagoon Coastal Plume, Brazil, Journal of Geophysical Research.
Marques, W. C, Fernandes, E. H. L., Moraes, B. C., Möller, O. O., and Malcherek, A., 2010b, Dynamics of the Patos Lagoon Coastal Plume and Its Contribution to the Deposition Pattern of the Southern Brazilian Inner Shelf, Journal of Geophysical Research, Vol. 115(C10), pp. 1-22.

Mello, L. F., Stringari, C. E., Eidt, R. T., and Marques, W. C., 2012, Desenvolvimento de Modelo Lagrangiano de Transporte de Óleo: Estruturação e Acoplamento ao Modelo Hidrodinâmico TELEMAC3D, Pesquisas Aplicadas em Modelagem Matemática, Unijui ed. (in Portuguese)

NOAA, 2000, ADIOS (Automated Data Inquiry for Oil Spills) version 2.0. Seattle: Hazardous Materials Response and Assessment Division, NOAA, Prepared for the U. S. Coast Guard Research and Development Center.

Pereira, R. C., and Soares-Gomes, A., 2002, Biologia Marinha, Inferência.

Proctor, R., Flather, R. A., and Elliot, A. J., 1994, Modelling Tides and Surface Drift in the Arabian Gulf - Application to the Gulf Oil Spill, Continental Shelf Research, Vol. 14, pp. 531-545.

Stiver, W., and Mackay, D., 1984, Evaporation Rate of Spills of Hydrocarbons and Petroleum Mixtures, Environmental Science and Technology, Vol. 18(11), pp. 834-840.

Stringari, C. E., Mello, L. F., Eidt, R. T., and Marques, W. C., 2012, Estudo Numérico Lagrangiano para Derrames de Óleo na Região Oceânica Adjacente ao Porto de Rio Grande - RS, in Conferência Internacional em Tecnologias Naval e Offshore: Ciência e Inovação, Rio Grande, RS. (in Portuguese)

Wang, H., and Huang, C. P., 1979, The Effect of Turbulence on Oil Emulsification, in: Workshop on Physical Behavior of Oil in the Marine Environment.

Wang, H., Yang, Z., Li, Y., Guo, Z., Sun, X., and Wang, Y., 2007, Dispersal Pattern of Suspended Sediment in the Shear Frontal Zone off Huanghe (Yellow River) Mouth, Continental Shelf Research, Vol. 27, pp. 854-871.

Received: September 30, 2012

Revised: October 30, 2012

Accepted: November 30, 2012 